\title{
Fatalism in breast cancer and performing mammography on women with or without a family history of breast cancer
}

\author{
Maryam Molaei-Zardanjani ${ }^{1}$, Mitra Savabi-Esfahani ${ }^{2^{*}}$ (D) and Fariba Taleghani ${ }^{3}$
}

\begin{abstract}
Background: Breast cancer is the most prevalent cancer in women, and in those with a positive family history, it is important to perform mammography. One of the probable barriers in doing mammography is fatalism.

Methods: This is a descriptive/cross-sectional study conducted on 400 women residing in Isfahan, Iran, randomly selected in 2017. Sampling was done randomly among the enrolled women in Health Integrity System. The data collection tool was a questionnaire regarding the demographic-fertility information and fatalism. The data analysis was done by SPSS software. A P-value $<0.05$ was considered statistically significant.

Results: The results showed that the mean rate of fatalism was $59.5 \pm 23.2$ in women with the experience of mammography, and $65.9 \pm 18.7$ in women without the experience. Moreover, the mean rate of fatalism was $73.1 \pm$ 15.2 in subjects with a family history of breast cancer, and $59.3 \pm 22.5$ in those no family history related to this condition. Accordingly, fatalism was statistically significant associated $(P<0.001)$ with a family history of breast cancer and experience of mammography. There was no significant relationship between demographic information and fatalism $(P>0.05)$.

Conclusion: The results indicated that fatalism in women with no experience of mammography was higher than in those with a positive history. Regarding the necessity of mammography in women with a family history of breast cancer, the required interventions seem to be essential to changing the viewpoints of women regarding the importance and effect of mammography as a screening method for breast cancer.
\end{abstract}

Keywords: Breast cancer, Family history, Fatalism, Mammography

\section{Background}

Breast cancer is the main cause of cancer-related mortality in women, hence a major health concern $[1,2]$. The risk of women being affected by breast cancer is increasing, such that one in eight women contracts the disease [3].

Although the incidence of breast cancer is high in developed countries, the rate of mortality in less developed countries has been reported to be relatively higher, due to not diagnosing breast cancer at its earliest stages and lack of access to proper caring facilities [4]. Early diagnosis of breast cancer is an

\footnotetext{
* Correspondence: M_savabi@nm.mui.ac.ir; Msavabi@yahoo.com

${ }^{2}$ Department of Midwifery and Reproductive Health, Nursing and Midwifery Care Research Center, Faculty of Nursing and Midwifery, Isfahan University of Medical Sciences, Isfahan, Iran

Full list of author information is available at the end of the article
}

important process which increases the survival rate (SR) [5], and studies have shown that there will be a reduction in mortality rate in the next 15 years through screening [6].

The most important step in a timely diagnosis of the disease is screening. Breast cancer has the required criteria for screening and early diagnosis [7]. American Cancer Society suggests that for an early diagnosis of breast cancer, all women aged 40-44 years should undergo screening mammography on an annual basis [8]. Women with a positive family history of breast cancer are more likely to develop cancer [9]. In this regard, Braithwaite et al., (2018) reported a first-degree family history resulted in an absolute increase in 5-year risk of breast cancer [10]. 
Despite the effect of breast cancer screening on reducing mortality, some women still do not consent to mammography as a method of screening. This is due to the lack of awareness, concerns about the outcome of mammography, the unavailability of mammography from women's point of view, the ostensible pain involved in the process, lack of knowledge on mammograms, negligence, lack of time, lack of understanding on the part of the spouse, and high costs [11-13].

One of the factors that may be negatively effective in the screening behavior is fatalism [14], considered as a socio-psychological factor in preventing cancer and fulfilling the screening behaviors [15]. Fatalism is the belief that conditions, such as disease or catastrophic events occur by a higher power (such as God), and cannot be avoided [14]. In fact, a doctrine that events are fixed in advance so that human beings are powerless to change them. (Webster's Dictionary 2019) [16].

According to the results noted by Ghahramanian et al., (2016) 10.8\% of women referred to health centers of Tabriz city in Iran, believed in fatalism. Moreover, the findings of some qualitative studies indicated that participating women mainly mentioned fatalism as a feeling of lack of control to prevent breast cancer [17, 18]. In this regard, Charkazi et al., (2013) showed that Iranian Turkmen women had high fatalism belief. They mentioned that fatalism is a significant belief in that society which could be considered as a barrier to breast cancer screening behaviors [15]. However, the results of Farmer et al., (2007) study showed that cancer fatalism was not as a direct correlate of mammography screening [19].

Although women without a family history may get breast cancer, but women with positive family history are at higher risk for getting breast cancer. To ensure that women, especially high-risk groups perform mammography for breast cancer screening, it is necessary to understand barriers that prevent women from having mammography.

Regarding the importance of mammography, especially in people with a positive family history of breast cancer, this study was done with the purpose of analyzing fatalism in breast cancer and mammography in women with or without a family history of breast cancer.

\section{Methods}

The present is a descriptive/cross-sectional study with a one-stage plan. One of the 13 districts Isfahan, Iran, was selected on a random basis. Using Eq. 1, the sample size was calculated to be 400 people.

$$
n=\left(\frac{Z_{1-a / 2} \times \delta}{d}\right)^{2}=\frac{4 \times \delta^{2}}{d^{2}}
$$

Sampling was done randomly among the enrolled women in Health Integrity System (SIB). The inclusion criteria were women over 40 years of age, and minimum reading and writing literacy and more.

The data was collected using a self-administered structured questionnaire comprised of demographic-fertility questions and questions regarding fatalism in breast cancer (Additional file 1).

The demographic-fertility information in this questionnaire included age, number of children, and level of education, marital status, family history of breast cancer, and experience of mammography $(n=6)$.

The questions regarding fatalism were rated on a 5item Likert scale (ranging from 1-strongly agree to 5strongly disagree). Some examples of questions included "I believe if someone gets breast cancer, they will die soon", "I believe if someone has a healthy diet, it cannot prevent breast cancer, they will get breast cancer", "I believe detection at early or advanced stages of breast cancer won't make any difference, they will die from it".

To determine the validity of fatalism questionnaire after studying the related books and papers, this questionnaire was given to 15 scholars and faculty members of the Nursing and Midwifery Faculty and the Faculty of Health in Isfahan University of Medical Sciences (IUMS). They reviewed the questionnaire for its content quality.

Test-retest method was used in the studied population to determine the reliability, with an interval of 2 weeks. Thus, the test was conducted at the beginning of the study and then 1 week later. The score of over 0.7 was considered reliable. The test-retest reliability was 0.8 .

The study began after getting necessary permissions from Isfahan University of Medical Sciences-Iran, with ethical committee code 395782.

Participation in this study was also based on written informed consent. After the purpose of the study was explained to the women, the researchers received the letter of consent from the sample. Then the questionnaires were completed by the self-administered technique in a calm and private environment.

The obtained data in this study were analyzed by using the descriptive information and SPSS (Ver. 16) software.

\section{Results}

The 400 women participated in this study. The majority of the women $(55.7 \%)$ belonged to the $40-49$ year age group, and $52.5 \%$ had four or more children. Most of the subjects (46.7\%) had elementary education; 95\% were married, and $15.5 \%$ had a positive family history of breast cancer (Table 1). 
Table 1 Demographic and fertility information of the subjects in the study

\begin{tabular}{|c|c|c|}
\hline Variable & No. & Percent \\
\hline \multicolumn{3}{|l|}{ Age } \\
\hline $40-49$ & 223 & 55.7 \\
\hline $50-59$ & 131 & 32.7 \\
\hline $60-69$ & 46 & 11.5 \\
\hline \multicolumn{3}{|l|}{ No. of children } \\
\hline $0-1$ & 52 & 13 \\
\hline $2-3$ & 138 & 34.5 \\
\hline 4 or more & 210 & 52.5 \\
\hline \multicolumn{3}{|l|}{ Education } \\
\hline Elementary & 187 & 46.7 \\
\hline High school & 183 & 45.7 \\
\hline University & 30 & 7.5 \\
\hline \multicolumn{3}{|l|}{ Marital status } \\
\hline Married & 380 & 95 \\
\hline Single & 11 & 2.8 \\
\hline Widow & 9 & 2.2 \\
\hline \multicolumn{3}{|c|}{ Experience of mammography } \\
\hline No & 276 & 69 \\
\hline Yes & 124 & 31 \\
\hline \multicolumn{3}{|c|}{ Family history of breast cancer } \\
\hline No & 338 & 84.5 \\
\hline Yes & 62 & 15.5 \\
\hline
\end{tabular}

The Pearson correlation coefficient showed no significant relation regarding the fatalism score between the women's age $(\mathrm{r}=-0.023, P=0.65)$ and the number of children $(\mathrm{r}=0.068, P=0.17)$. Moreover, the results from the Spearman correlation indicated that the fatalism score had no significant relation with education in women $(\mathrm{r}=-0.105, \quad P=0.13)$. The results further showed that there was no significant relation between fatalism score and marital status $(\mathrm{r}=-0.21, P=0.16)$ (Table 2).

There was no significant relationship between demographic information and fatalism $(P>0.05)$.

The mean rates for fatalism were $59.5 \pm 23.2$ in women with the experience of mammography, and 65.9 \pm 18.7 in women with no experience of mammography.

Table 2 Correlation coefficient between demographic information and fatalism

\begin{tabular}{lll}
\hline Variables & $\mathrm{R}$ (Correlation Coefficient) & $P$ Value \\
\hline Age & -0.023 & 0.65 \\
No. of children & 0.068 & 0.17 \\
Education & -0.105 & 0.13 \\
Marital status & -0.21 & 0.16 \\
\hline
\end{tabular}

The statistical analysis showed that fatalism in women without the experience was significantly higher than those with the history of mammography $(P<0.001)$.

Furthermore, the mean score of fatalism in women with a family history of breast cancer was $73.1 \pm 15.2$, and that for subjects without the history was $59.3 \pm 22.5$. Fatalism had a statistically significant association with family history of breast cancer $(P<0.001)$ (Table 3$)$.

\section{Discussion}

Our findings showed that the mean score of fatalism in women with no experience of mammography was higher. Thus, women believing in fatalism are less likely to undergo mammography. In this regard, Liang et al. [20] showed that the higher the belief in fatalism is, the lower the inclination towards screening for breast cancer will be, which is in line with the present study. Moreover numerous studies indicated that there is a relationship between health beliefs and behavior. They revealed screening rates were low among women with score highest on fatalism [21, 22].

This study also showed that fatalism is more common in women with a positive family history of breast cancer, which is in accordance with Tuzcu et al. [23]. They indicated that the belief in fatalism was higher in women with a family history of breast cancer than women without a family history. In this regard the results of the study by Opoku et al. [24] showed some participants believed breast cancer is an incurable disease and if someone gets breast cancer, they will die. The researchers mentioned that such beliefs are because many patients present for treatment at advanced stages and doctors are not able to treat them. In addition the findings of study Tracy et al. [25] showed that women who experienced a breast cancer survivor had more positive beliefs about mammography.

It seems that the lack of screening or detection at early stages of breast cancer in family members, and consequently, unsuccessful treatment of disease at advanced stages may lead to increased fatalism in women with a family history of breast cancer. Therefore, the results of

Table 3 Mean and Standard Division (SD) of fatalism scores in different groups

\begin{tabular}{|c|c|c|c|c|}
\hline \multirow[t]{2}{*}{ Groups } & \multicolumn{2}{|c|}{ Fatalism } & \multirow[t]{2}{*}{ t-test } & \multirow[t]{2}{*}{$P$-value } \\
\hline & Mean & SD & & \\
\hline \multicolumn{5}{|c|}{ Family history of breast cancer } \\
\hline Yes & 73.1 & 15.2 & 21.51 & $<0.001$ \\
\hline No & 59.3 & 22.5 & & \\
\hline \multicolumn{5}{|c|}{ Experience of mammography } \\
\hline Yes & 59.5 & 23.2 & 7.24 & $<0.001$ \\
\hline No & 65.9 & 18.7 & & \\
\hline
\end{tabular}


present study may be due to inadequate understanding about breast cancer disease, as well the advantages of mammography as a screening technique in women.

Although the results of the study by Banning et al. [2] showed that fatalism was higher in people with lower education, in the current research, no significant relation was observed between the demographic factors (age, no. of children, education, and marital status); however, positive family history has been reported as one of the variables related to fatalism.

Cross-sectional basis and self-reporting by subjects were among the limitations of this research, hence the necessity of more extensive studies in this respect.

\section{Conclusions}

Women with a family history of breast cancer, who have were more likely to believe in fatalism, may not consider mammography an effective screening method; thus, further interventions are recommended so as to change the viewpoints of women in this regard.

\section{Additional file}

Additional file 1: Fatalism questionnaire (Persian and English versions). (DOCX $16 \mathrm{~kb})$

\section{Abbreviations}

IUMS: Isfahan University of Medical Sciences; SIB: Health Integrity System; SR: Survival rate

\section{Acknowledgments}

We would like to acknowledge the help of all the women involved in this study, and those conducing to the research.

\section{Authors' contributions}

MMZ, MSE and FT were involved in the study design. MMZ and MSE collected all data and analyzed the data for the study purpose. MMZ, FT and MSE contributed to drafting and revising the manuscript. All authors read and approved the final manuscript.

\section{Funding}

This research was not funded by any project grant

\section{Availability of data and materials}

The datasets generated during the current study are available from the corresponding author on reasonable request.

\section{Ethics approval and consent to participate}

The present study was approved by the Research Department and Ethica Committee for Research in Isfahan University of Medical Sciences (No: IR.MUI.REC.1395.3.782). Participation in this study was completely anonymous and based on written informed consent.

\section{Consent for publication}

Not applicable.

\section{Competing interests}

The authors declare that they have no competing interests.

\section{Author details}

${ }^{1}$ Faculty of Nursing and Midwifery, Isfahan University of Medical Sciences, Isfahan, Iran. ${ }^{2}$ Department of Midwifery and Reproductive Health, Nursing and Midwifery Care Research Center, Faculty of Nursing and Midwifery,
Isfahan University of Medical Sciences, Isfahan, Iran. ${ }^{3}$ Faculty of Nursing \&Midwifery, Nursing\& Midwifery care research center, Isfahan University of Medical Sciences, Isfahan, Iran

Received: 10 April 2019 Accepted: 13 August 2019

Published online: 13 September 2019

\section{References}

1. Andsoy II, Gul A. Breast, cervix and colorectal cancer knowledge among nurses in Turkey. Asian Pac J Cancer Prev. 2014;15(5):2267-72.

2. Banning $M$, Shia N. Perceptions of breast cancer screening in older Chinese women: a meta-ethnography. Global J Breast Cancer Res. 2014;2:8-18.

3. American Cancer Society. Breast Cancer facts and figures 2017-2018. Atlanta: American Cancer Society; 2017.

4. Ferlay J, Soerjomataram I, Dikshit R, Eser S, Mathers C, Rebelo M, et al. Cancer incidence and mortality worldwide: sources, methods and major patterns in GLOBOCAN 2012. Int J Cancer. 2015;136(5):E359-E86.

5. Yousuf SA. Breast cancer awareness among Saudi nursing students. J King Abdulaziz Univ: Medical Sciences. 2010;98(279):1-24.

6. Yucel SC, Orgun F, Tokem Y, Avdal EU, Demir M. Determining the factors that affect breast cancer and self-breast examination beliefs of Turkish nurses in academia. Asian Pac J Cancer Prev: APJCP. 2014;15(3):1275-80.

7. Naghibi SA, SHojaizadeh D, Yazdani CJ, Montazeri A. Breast cancer preventive behaviors among Iranian women: a systematic review. PAYESH. 2015;14(2):181-91.

8. Oeffinger KC, Fontham ET, Etzioni R, Herzig A, Michaelson JS, Shih Y-CT, et al. Breast cancer screening for women at average risk: 2015 guideline update from the American Cancer Society. JAMA. 2015;314(15):1599-614.

9. Oncology ASoC. Statement of the American Society of Clinical Oncology. Genetic testing for cancer susceptibility. J Clin Oncol. 1999;14:1730.

10. Braithwaite D, Miglioretti DL, Zhu W, et al. Family history and breast Cancer risk among older women in the breast Cancer surveillance consortium cohort. JAMA Intern Med. 2018:178(4):494-501.

11. Hatefnia E, Niknami S. Predictors of mammography among employed women by HBM model. J Zabol Univ Med Sci Health Serv. 2013:5(1):47-56.

12. O'Leary D, PB AMZ. 19: Investigation of a novel method for breast discomfort reduction during mammography. Breast Cancer Res. 2013: 15(1):P19

13. Yılmaz M, Kiymaz Ö. Anxiety and pain associated with process mammography influence of process information before. J Breast Health 2010;6(2):62-8

14. Akhigbe A, Akhigbe K. Effects of health belief and cancer fatalism on the practice of breast cancer screening among Nigerian women. Intech Open Access Publisher. 2012

15. Charkazi A, Samimi A, Razzaghi K, Kouchaki GM, Moodi M, Meirkarimi K, et al. Adherence to recommended breast cancer screening in Iranian Turkmen women: the role of knowledge and beliefs. ISRN Prev Med. 2013;2013: 581027

16. Webster's Dictionary. Fatalism. [Accessed 27 June 2019]. https://www. webster-dictionary.org/definition/Fatalism.

17. Ghahramanian A, Rahmani A, Aghazadeh AM, Mehr LE. Relationships of fear of breast Cancer and fatalism with screening behavior in women referred to health centers of Tabriz in Iran. Asian Pac J Cancer Prev. 2016:17(9):4427-32.

18. Savabi-Esfahani M, Taleghani F, Tabatabaeian M, Noroozi M, Lynge E. A qualitative exploration of personality factors in breast cancer screening behavior. Soc Behav Personal Int J. 2018;46(1):91-7.

19. Farmer D, Reddick B, Jackson SA. Psychosocial correlates of mammography screening in older African American women. Oncol Nurs Forum. 2007:34(1):117-23.

20. Liang W, Wang JH, Chen M-Y, Feng S, Lee M, Schwartz MD, et al. Developing and validating a measure of Chinese cultural views of health and cancer. Health Educ Behav. 2008;35(3):361-75.

21. Drew EM, Schoenberg NE. Deconstructing fatalism: ethnographic perspectives on Women's decision making about Cancer prevention and treatment. Med Anthropol Q. 2011;25(2):164-82

22. Lannin DR, Mathews HF, Mitchell J, Swanson MS, Swanson FH, Edwards MS. Influence of socioeconomic and cultural factors on racial differences in late-stage presentation of breast Cancer. JAMA. 1998; 279(22):1801-7.

23. Tuzcu A, Bahar Z. Barriers and facilitators to breast cancer screening among migrant women within Turkey. J Transcult Nurs. 2015;26(1):47-56. 
24. Opoku SY, Benwell M, Yarney J. Knowledge, attitudes, beliefs, behaviour and breast cancer screening practices in Ghana, West Africa. Pan Afr Med J. 2012;11:28.

25. Tracy KA, Quillin JM, Wilson DB, Borzelleca J, Jones RM, McClish D, et al. The impact of family history of breast cancer and cancer death on women's mammography practices and beliefs. Genet Med. 2008;10(8):621.

\section{Publisher's Note}

Springer Nature remains neutral with regard to jurisdictional claims in published maps and institutional affiliations.

Ready to submit your research? Choose BMC and benefit from:

- fast, convenient online submission

- thorough peer review by experienced researchers in your field

- rapid publication on acceptance

- support for research data, including large and complex data types

- gold Open Access which fosters wider collaboration and increased citations

- maximum visibility for your research: over $100 \mathrm{M}$ website views per year

At BMC, research is always in progress.

Learn more biomedcentral.com/submissions 